\title{
Design and Implementation of Embedded Water Quality Control and Monitoring System for Indoor Shrimp Cultivation
}

\author{
Oskar Natan, Agus Indra Gunawan, Bima Sena Bayu Dewantara \\ Politeknik Elektronika Negeri Surabaya \\ Jl. Raya ITS - Kampus PENS, Sukolilo, Surabaya, 60111 \\ Email : theoskarnatan@gmail.com, agus_ig@pens.ac.id, bima@pens.ac.id
}

\begin{abstract}
Maintaining the water quality of a pond is one of the main issues on aquaculture management. Water quality represents the condition of a pond based on several water parameters such as dissolved oxygen (DO), temperature, $\mathrm{pH}$, and salinity. All of these parameters need to be strictly supervised since it affects the life-sustainability of cultivated organisms. However, DO is said to be the main parameter since it affects the growth and survival rate of the shrimp. Therefore, a water quality control and monitoring system is needed to maintain water parameters at acceptable value. The system is developed on a mini-PC and microcontroller which are integrated with several sensors and actuator forming an embedded system. Then, this system is used to collect water quality data that is consisting of several water parameters and control the DO as the main parameter. In accordance with the stability needs against the sensitive environment, a fuzzy logic-based controller is developed to maintain the DO rate in the water. This system is also equipped with SIM800 module to notice the farmer by SMS, built-in wifi module for web-based data logging, and improved with Android-based graphical user interface (GUI) to perform user-friendly monitoring. From the experiment results, a fuzzy controller that is attached to the system can control the DO at the acceptable value of $6 \mathrm{ppm}$. The controller is said to have high robustness since its deviation for long-time use is only $0.12 \mathrm{ppm}$. Another test shows that the controller is able to overcome the given disturbance and easily adapt when the DO's set point is changed. Finally, the system is able to collect and store the data into cloud storage periodically and show the data on a website.
\end{abstract}

Keywords: monitoring system, embedded system, fuzzy logic controller, water quality, shrimp cultivation.

\section{INTRODUCTION}

Indoor shrimp cultivation is currently a popular farming technique which is used by a lot of shrimp farmers in Indonesia. The base concept of this farming method is cultivating the aquatic organism in a small pond 
environment to control the water parameters easily [1]. The environmental condition of a shrimp pond can be assessed by its water quality data which is described by several water parameters such as $\mathrm{DO}, \mathrm{pH}$, salinity, and temperature. DO defines the amount of dissolved oxygen in a pond. $\mathrm{pH}$ represents the scale of water acidity from 0 to 14 . Salinity expresses the saltiness or amount of salt dissolved in a body of water. Based on [2], The minimum limit of DO for shrimp cultivation process is $3 \mathrm{ppm}$ or $3 \mathrm{mg} / \mathrm{L}$, it means that at least there is $3 \mathrm{mg}$ of oxygen which is dissolved in $1 \mathrm{~L}$ of water. $\mathrm{pH}$ levels for shrimp cultivation process must be in the range of $7-8.5$. The salinity of water in the pond must be in the range of $0-35$ ppt or $0-35 \mathrm{~g} / \mathrm{L}$, it means that the amount of salt in $1 \mathrm{~L}$ of water must be in the range of $0-35 \mathrm{~g}$. Meanwhile, the allowed temperature for the cultivation process is $26-35^{\circ} \mathrm{C}$. All of these parameters need to be strictly maintained to support life sustainability of the shrimp. However, the farmer can't keep-an-eye continuously to ensure that the water condition is good enough for cultivation.

Therefore, a water quality control and monitoring (WQCM) system is needed to overcome supervision and maintenance problem. The monitoring function in WQCM system is developed to measure $\mathrm{DO}, \mathrm{pH}$, salinity, and temperature of water in the pond continuously. The system is made from a mini-pc and microcontroller forming an embedded system with several appropriate sensors and modules attached in it. Besides measuring the water parameters, this system is assigned to give early warning information if it detects unacceptable water condition. To perform this function, the system is equipped with SIM800 module to notice the farmer by SMS if any bad conditions occurred. In accordance with the need for automatic data logging, the system also connected to the internet to send the water quality data to a website periodically. This mechanism is far more effective than using human intervention to do aquaculture management task. However, another problem is appeared due to the lack of cultivation area. The high density of shrimp in the pond can make the DO rate decreased significantly and cause a high risk of massive shrimp death. This problem has to be well-managed since DO plays an important role in affecting the survival rate of a shrimp [3][4][5]. Therefore, a control system is also needed to maintain DO at acceptable value for cultivation process [6]. As the work in [1], the DO control mechanism in WQCM system is flushing the air into the pond by using an aerator. Then, several aeration stones are attached at the end of the air pipe to make a smoother air bubbles. The standard value for DO rate to keep up the survival rate and growth of the shrimp is $6 \mathrm{ppm}$.

In this research, a WQCM system for supervising and control the water quality in a pond easily is presented. The system consists of several electronics modules and circuits. For real implementation purpose, the system is applied to an indoor shrimp pond to perform water quality control and data acquisition. With this mechanism, the farmer is able to know about their pond condition and receive early warning notification even they are not in the place. DO as the main parameter can be controlled with stability so that the high risk 
of shrimp death can be prevented. Finally, the system is improved with Android-based GUI which is able to show the data interactively.

\section{RELATED WORKS}

There is plenty of control and monitoring system that has been developed in several kinds of research. In [7], an optimal PID control is used to manage DO concentration in the wastewater treatment plant. An expert system is also developed in [8] to control the DO rate in wastewater aerobics treatment process. A fuzzy logic controller can be used to control the DO concentration in an activated sludge process [9] and SBR water treatment process [10]. Another approach like a heuristic method such as neuraladaptive control is applied to control the DO of activated sludge bioreactors in [11]. Then, a nonlinear control is implemented to control the DO rate of Pseudomonas Putida bacterium fermentation in [12]. Several works about monitoring systems also have been developed in [13][14][15][16][17] to do continuously monitoring task with ease. In another hand, IoT-based system is performed to give effective monitoring and data recording in [18][19][20][21]. All of these systems have been proven to work properly in replacing human intervention on monitoring, supervising, and acquiring the data.

\section{ORIGINALITY}

This research is giving detail development of WQCM system which is used to control and supervise the water quality of a shrimp pond. The water quality itself is represented by the value of $\mathrm{DO}, \mathrm{pH}$, salinity, and temperature. Several particular functions such as DO control, early warning notification, water quality monitoring, data logging, etc are integrated into this system to support the farmer in managing the cultivation. The system is equipped with appropriate sensors and modules to perform pond supervising. A control method called fuzzy logic is also used to control an aerator in maintaining DO at an acceptable value. By using WQCM system, the risk of shrimp death and losses are expected can be reduced. In other words, the cultivation results are expected to be better than the current traditional method which is not effective and causing cultivation problems. Therefore, the novelty and contribution of this research is the real implementation of the proposed system (WQCM) to overcome the aquaculture management problem, especially on indoor shrimp cultivation. Further analysis of system performance including the fuzzy controller during cultivation is described in experiment and analysis section.

\section{SYSTEM DESIGN}

As mentioned in the previous section, there are several particular systems that have their own specific function in the cultivation process. The grand design of indoor cultivation with its particular systems can be seen in Fig. 1. There are several things to be concerned with developing the system. As the first step, a calibration for each sensor that is used to measure water quality parameters is performed. Then, the topology and work mechanism of 
the system that shows how the water parameter is measured and stored into cloud storage is well-described. A clear description about fuzzy controller development for DO rate management is also given.

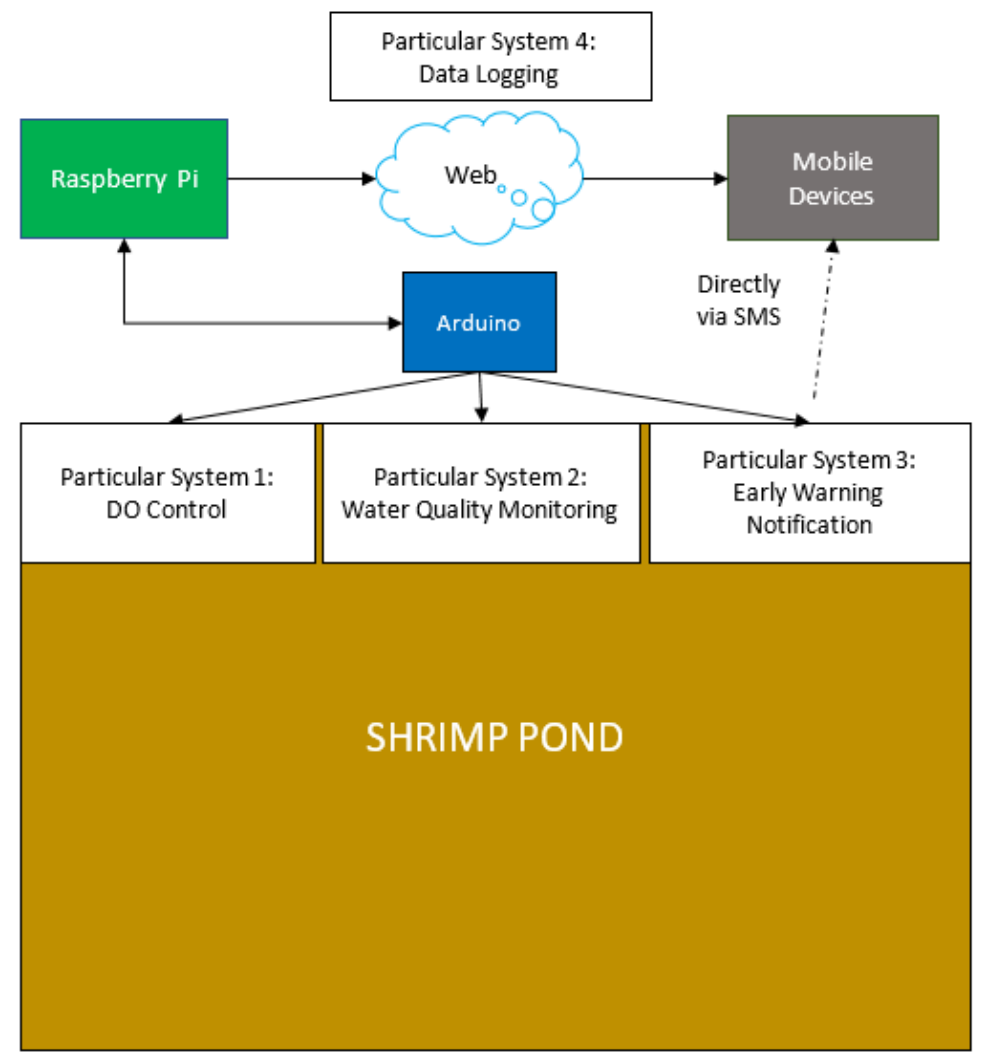

Figure 1. Grand Design of Indoor Cultivation with Its Particular Systems

\subsection{Sensor Calibration}

There are 4 kinds of sensors which are used to measure the water quality of the pond, that are: DO, pH, salinity and temperature sensors. In order to ensure that all sensors work properly and perform a correct measurement, each sensor is calibrated using several methods based on their characteristic.

First, a statistical approach named linear regression is used to calibrate $\mathrm{pH}$ and salinity sensor. The sensor generates an analog signal to interpret the measured quantities. Then, the analog signal is processed by an analog to digital converter (ADC) in Arduino microcontroller to obtain its digital value. By using simple linear regression, the equation which shows the correlation between measured $\mathrm{pH}$ or salinity with the ADC value can be obtained. To perform this, 3 kinds of water solution with different $\mathrm{pH}$ and salinity is made by mixing water with salt and pH buffer solution as shown in Fig. 2. 


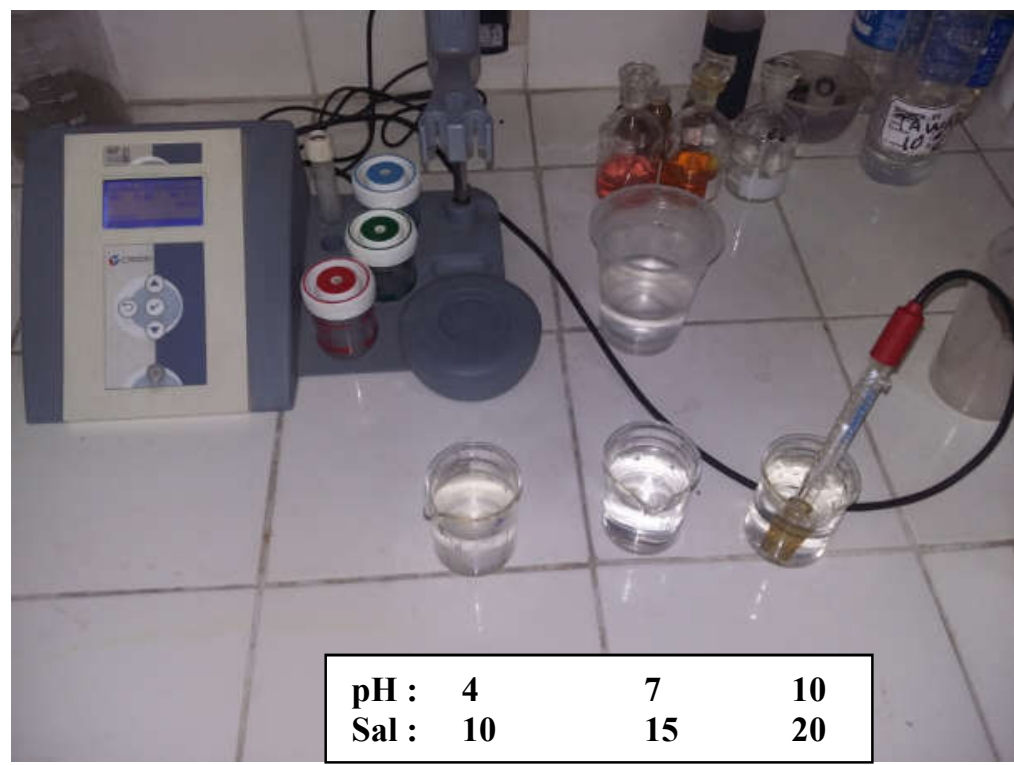

Figure 2. Three Kinds of Water Solution

Then, a standard measurement module named CRISON is used to measure $\mathrm{pH}$ and refractometer to measure water salinity. After getting the actual data, $\mathrm{pH}$ and salinity sensors are placed into water to get the ADC values and use linear regression to obtain the equation or calibration model. The regression line for $\mathrm{pH}$ and salinity are shown in Fig. 3 and Fig. 4.

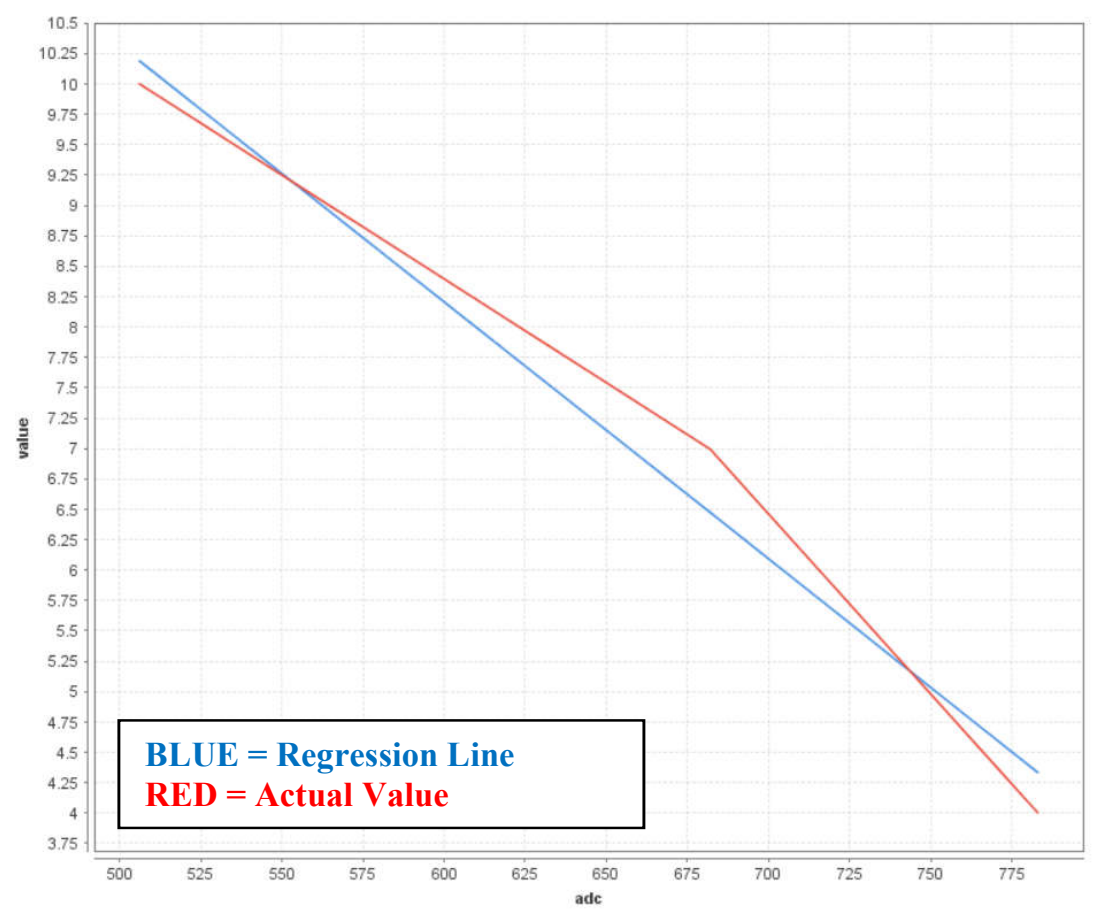

Figure 3. pH Calibration Model 


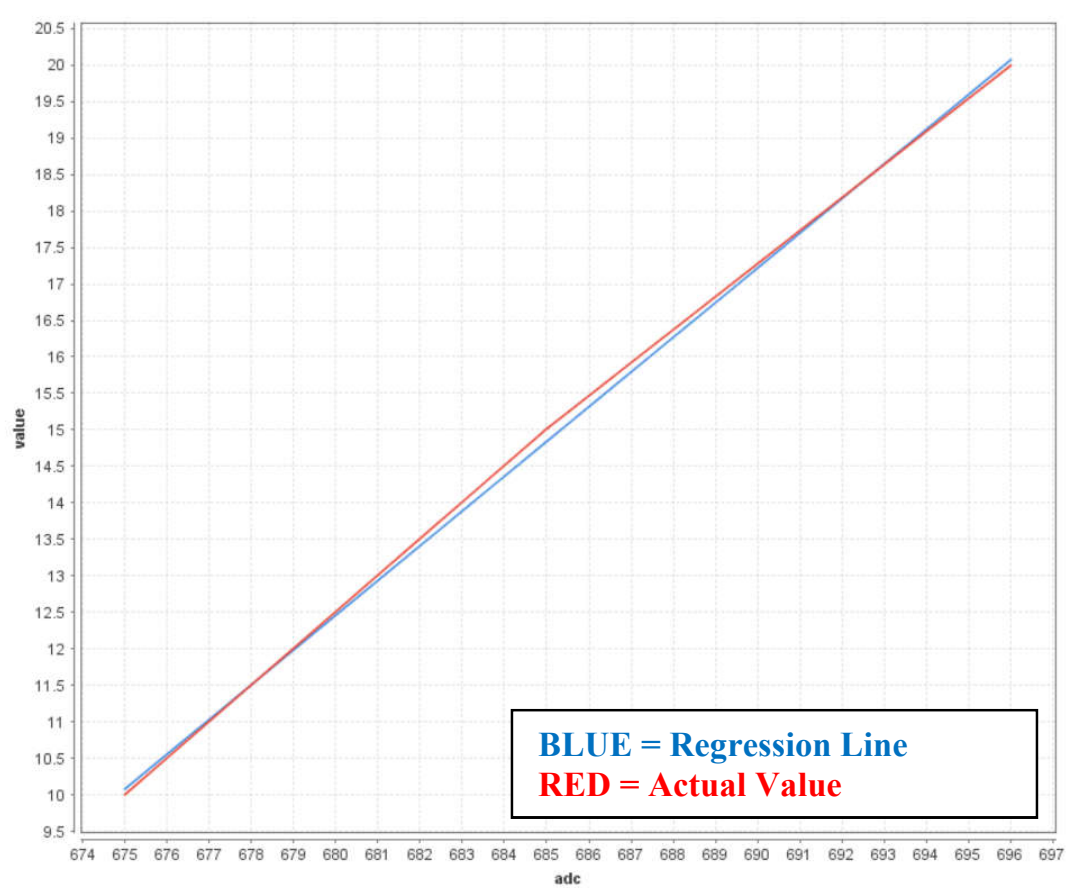

Figure 4. Salinity Calibration Model

Meanwhile, the calibration model of $\mathrm{pH}$ sensor and salinity sensor are shown in equation $1-2$ respectively. These equations are implemented in Arduino so that the system is able to measure $\mathrm{pH}$ and salinity precisely by using the sensors.

$$
\begin{aligned}
& p H=0.021 \times A D C+20.892 \\
& \text { salinity }=0.476 \times A D C \quad 311.103
\end{aligned}
$$

Different from $\mathrm{pH}$ and salinity, in order to measure water temperature, a module named AZ-8403 is used. To ensure that the module works correctly, it is compared to a thermometer which is used as the standard temperature measurement device. Then, a comparison between the devices is performed in the temperature range of $26^{\circ} \mathrm{C}-35^{\circ} \mathrm{C}$ which is the acceptable value for shrimp cultivation. The temperature comparison results between AZ-8403 and thermometer are shown in Table 1 . It can be concluded that AZ-8403 is good enough to measure temperature with a maximum error percentage of $0.004 \%$.

\begin{tabular}{|c|c|c|c|}
\hline Condition & $\mathrm{AZ}-8403\left({ }^{\circ} \mathrm{C}\right)$ & Temperature $\left({ }^{\circ} \mathrm{C}\right)$ & Error (\%) \\
\hline Cold & 26.2 & 26.3 & 0.004 \\
\hline Below Normal & 28.5 & 28.5 & 0.000 \\
\hline Normal & 30.2 & 30.3 & 0.003 \\
\hline Warm & 32.1 & 32.2 & 0.003 \\
\hline Hot & 34.8 & 34.8 & 0.000 \\
\hline
\end{tabular}

Table 1. Temperature Comparison Result 
In this research, only the DO rate is controlled since it is the main parameter in the cultivation process. Thus, calibration of the DO sensor is very important to be done since it can affect the performance of the controller. Based on the work in [1], in order to know its characteristics, the sensor is placed at six different points in the pond and compare the gathered data. The measurement is performed with using standard measurement instrument which is AZ-8403 module. The purpose of this step is to ensure that DO value is the same in every placement point when there is no aeration process performed. The top and side view of placement point(red dots) and four aeration stone (black dots) are shown in Fig. 5. and Fig. 6 respectively.

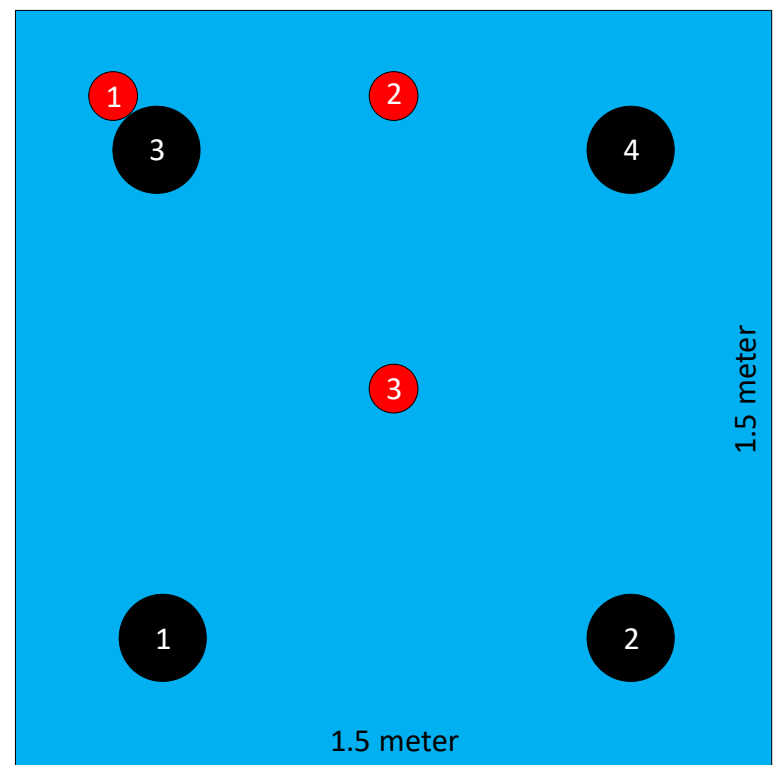

Figure 5. Top View of The Pond and Sensor Placement

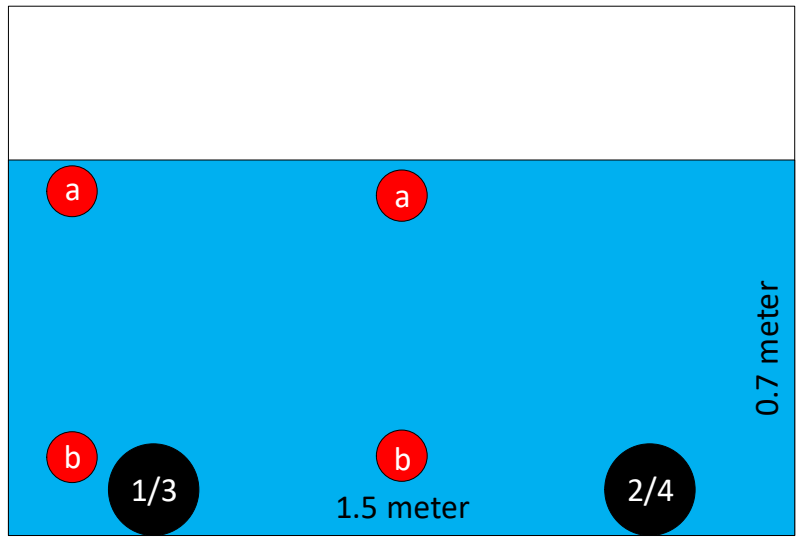

Figure 6. Side View of The Pond and Sensor Placement

Based on the DO measurement results which are shown in Table 2, we obtained the measurement deviation of $0.0303 \mathrm{ppm}$. At this value, we can conclude that DO measurements are the same at any point in the pond. 
Table 2. DO Value at 6 Different Placement Point

\begin{tabular}{|c|c|c|}
\hline No. & Measurement Point & Value (ppm) \\
\hline 1 & Corner - Surface (1a) & 5.12 \\
\hline 2 & Corner - Bottom (1b) & 5.15 \\
\hline 3 & Center-Edge - Surface (2a) & 5.08 \\
\hline 4 & Center-Edge - Bottom (2a) & 5.13 \\
\hline 5 & Center - Surface (3a) & 5.07 \\
\hline 6 & Center - Bottom (3b) & 5.11 \\
\hline \multicolumn{2}{|c|}{ Standard Deviation } & 0.0303 \\
\hline
\end{tabular}

After knowing the DO characteristic, the calibration process can be continued. There are several methods that can be used to calibrate the DO sensor just like in [22][23][24]. As in [1], a machine learning algorithm called support vector regression with radial basis function kernel is used to make a calibration model which describe the relation between DO value and sensor signal. The algorithm has $\mathrm{C}$ and Gamma parameters and they are optimized by using the grid search algorithm. To obtain the data for modeling purpose, DO and sensor's ADC (analog to digital conversion) value are measured from the lowest value $(5.4 \mathrm{ppm})$ to maximum value $(7.6 \mathrm{ppm})$. The sensor's response and the regression line by using the model is shown in Fig. 7. With using this model, the RMSE (root mean square error) of DO prediction is only 0.045 .

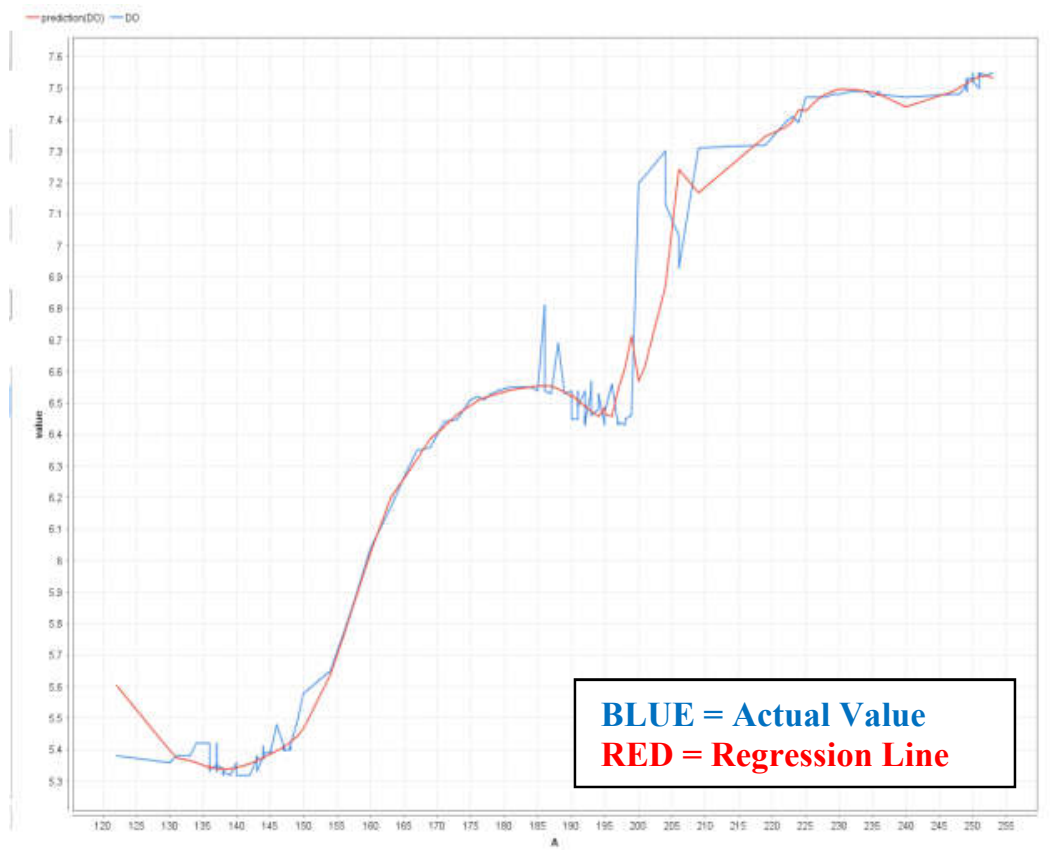

Figure 7. DO Calibration Model

\subsection{Monitoring System}

After performing calibration for each sensor, we connect every sensors and modul to the microcontroller in acquiring the water parameters data. Then the data is stored to the cloud storage and processed for early warning 
notice or water quality control purposes. Block diagram of this system which shows the connectivity between equipment is shown in Fig. 8. Water parameters which are $\mathrm{pH}$, salinity, $\mathrm{DO}$, and temperature is measured by the appropriate sensors. Temperature measurement is performed by AZ8403, then the data of temperature are sent to Arduino using serial communication. Thus, we use RS232 to TTL serial converter to transfer the data from AZ-8403 to the microcontroller. Meanwhile, DO, pH and salinity measurement are performed by analog sensors. However, the generated signals from each sensor are very weak to be read by the ADC, so a simple amplifier circuit is used to amplify the analog signal with the range of $0-5 \mathrm{~V}$. By using the calibration model that has been obtained in the previous subchapter, the ADC value can be converted to the actual value of $\mathrm{pH}$ and salinity. All of these measured parameters are shown in 20x4 LCD so that the farmer can know the water condition at any time.

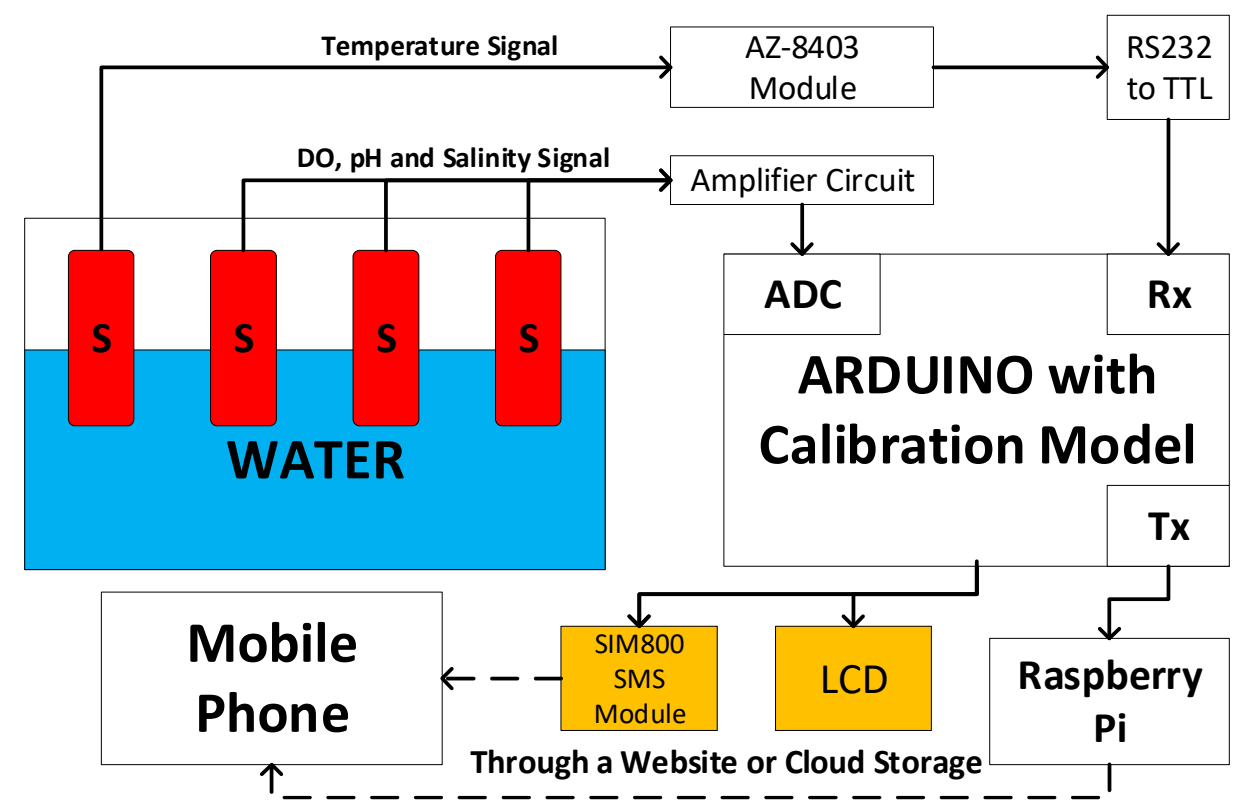

Figure 8. Block Diagram of Monitoring System.

After gathered by Arduino, water parameters data are sent to the raspberry pi which is used to upload the retrieved data into cloud storage. This mini-PC has built-in wifi module so that it is able to connect to a network. In this process, water parameters data is sent as a packet data which have a delimiter. Then, raspberry will separate the packet data by its delimiter to know which ones are $\mathrm{pH}$, temperature, salinity, or DO. We can illustrate this packet data by Fig. 9. After that, the data which contains the values of $\mathrm{pH}, \mathrm{DO}$, salinity, $\mathrm{pH}$, and measurement time is sent to a website periodically.

\begin{tabular}{|c|c|c|c|c|c|c|c|}
\hline $\begin{array}{c}\text { DATA 1 } \\
\text { (DO) }\end{array}$ & $\begin{array}{c}\mathrm{x} \\
\text { Delimiter }\end{array}$ & $\begin{array}{c}\text { DATA 2 } \\
(\mathbf{p H})\end{array}$ & $\begin{array}{c}\mathrm{x} \\
\text { Delimiter }\end{array}$ & $\begin{array}{c}\text { DATA 3 } \\
\text { (Temp.) }\end{array}$ & $\begin{array}{c}\mathrm{x} \\
\text { Delimiter }\end{array}$ & $\begin{array}{c}\text { DATA 4 } \\
\text { (Sal.) }\end{array}$ & $\begin{array}{c}\mathrm{x} \\
\text { Delimiter }\end{array}$ \\
\hline
\end{tabular}

Figure 9. Ilustration of Packet Data. 
Then, the most common HTTP method called GET method is used to manage the received data which is uploaded by the raspberry pi. Then the received data is saved in cloud storage or database. Whenever the farmer wants to know about the pond condition, the stored data are called again and displayed on a GUI which is developed based on Android smartphone. The design of Android-based GUI is shown in Fig. 10. With this many features which are developed in this research, a farmer can keep-an-eye to their pond condition even though they are not in place.

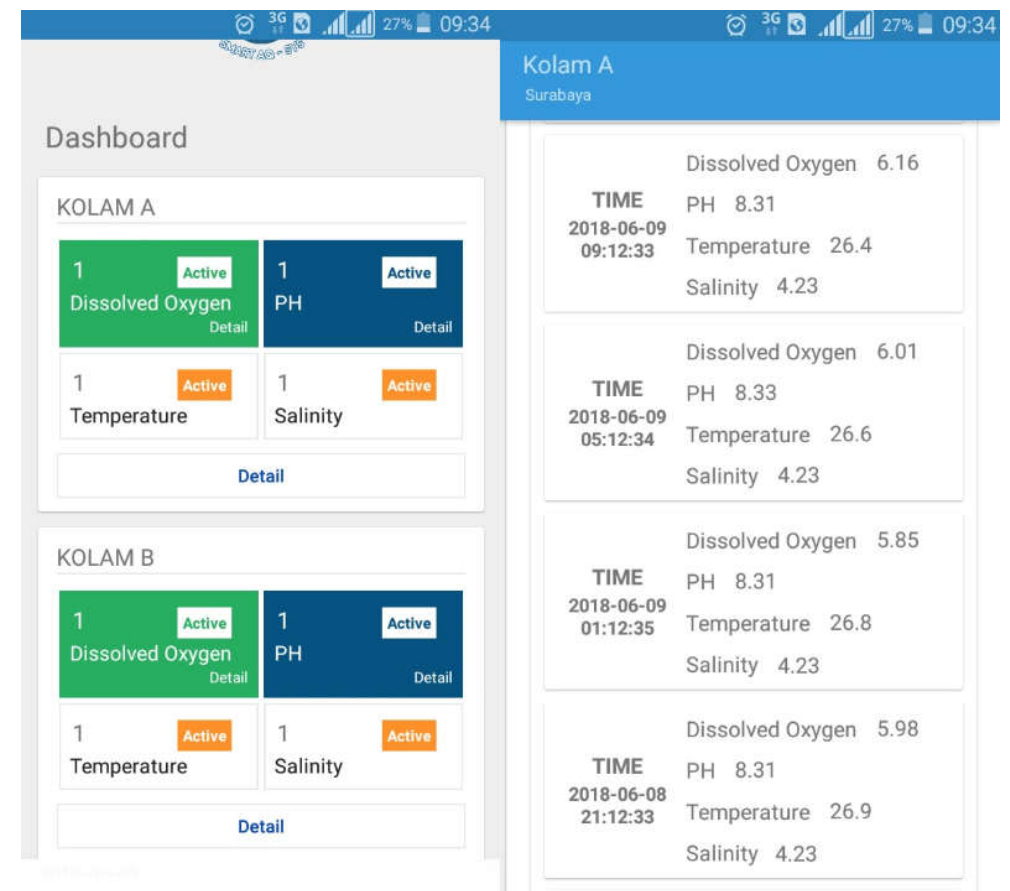

Figure 10. Design of Android-based GUI.

\subsection{Early Warning System}

As mentioned in the previous chapter, the system is able to give a warning notice to the farmer if any bad condition occurred. This system is equipped with SIM800 module to send an early warning notice by SMS once a time when a bad condition occurrs. The system will detect a bad condition and send an early warning SMS if measured water parameters are not in their acceptable values. The SMS is contained of kind of occurred bad condition and its recommendation. Based on [2], the acceptable values for shrimp cultivation are shown in Table 3.

Table 3. Acceptable Values for Shrimp Cultivation

\begin{tabular}{|c|c|c|}
\hline Water Parameter & Maximum Limit & Minimum Limit \\
\hline DO & - & $3 \mathrm{ppm}$ \\
\hline Temperature & $35^{\circ} \mathrm{C}$ & $26^{\circ} \mathrm{C}$ \\
\hline Salinity & $35 \mathrm{ppt}$ & $0 \mathrm{ppt}$ \\
\hline $\mathrm{pH}$ & 8.5 & 7 \\
\hline
\end{tabular}


Based on Table 3, several rules are made for early warning notice by states the threshold values for each parameter. Several recommendations and preventive actions based on [2] are given to complete the early warning function. The threshold value for each parameter and its recommendation are shown in Table 4.

Table 4. Early Warning Rules and Recommendation

\begin{tabular}{|c|c|c|l|}
\hline $\begin{array}{c}\text { Water } \\
\text { Parameter }\end{array}$ & $\begin{array}{c}\text { Warning } \\
\text { Condition }\end{array}$ & $\begin{array}{c}\text { Send } \\
\text { SMS }\end{array}$ & \multicolumn{1}{|c|}{ Recommendation } \\
\hline \multirow{2}{*}{$\mathrm{DO}$} & $<4 \mathrm{ppm}$ & Yes & Turn on extra aerator \\
\hline \multirow{2}{*}{$\mathrm{pH}$} & $<7.5$ & Yes & Add $\mathrm{CaCO}_{3}$ \\
\cline { 2 - 4 } & $>8$ & Yes & Add distilled water \\
\hline \multirow{2}{*}{ Salinity } & $<15 \mathrm{ppt}$ & Yes & Add sea water / salt \\
\cline { 2 - 4 } & $>25 \mathrm{ppt}$ & Yes & Add distilled water \\
\hline \multirow{2}{*}{ Temperature } & $<26^{\circ} \mathrm{C}$ & Yes & Turn on heater \\
\cline { 2 - 4 } & $>30^{\circ} \mathrm{C}$ & Yes & Turn off heater \\
\hline
\end{tabular}

\subsection{Control System}

An actuating device is needed to maintain the water quality, especially for DO parameter. Based on [1], an electronic device called aerator is used to flush the air into the pond by using a pipeline and aeration stones. The important thing that needs to be done before designing the fuzzy controller is knowing the working voltage of the aerator. To obtain its characteristic, several tests are performed to the aerator by giving various AC voltage from an auto-transformer. Then, visual justification is used to look at the bubble appearance in the water. The experiment result that shows input voltage value and bubble appearance are shown in Table 5.

Table 5. Bubble Appearance at Various Voltage

\begin{tabular}{|c|c|c|}
\hline No. & Input Voltage (V) & Bubbles \\
\hline 1 & 110.8 & No \\
\hline 2 & 125.6 & No \\
\hline 3 & 138.9 & No \\
\hline 4 & 140.7 & No \\
\hline 5 & 150.1 & No \\
\hline 6 & 164.2 & Yes \\
\hline 7 & 173.5 & Yes \\
\hline 8 & 180.1 & Yes \\
\hline 9 & 190.6 & Yes \\
\hline 10 & 200.8 & Yes \\
\hline 11 & 205.2 & Yes \\
\hline 12 & 210.7 & Yes \\
\hline 13 & 220.5 & Yes \\
\hline
\end{tabular}

Based on Table 5, it can be concluded that the bubble appearance is achieved when the input voltage is in the range of $164.2 \mathrm{~V}-232.1 \mathrm{~V}$. As 
mentioned before, the aerator is worked by flushing the air into the pond until the measured DO rate is the same as the set point value. The diagram process of this control system is shown in Fig. 11.

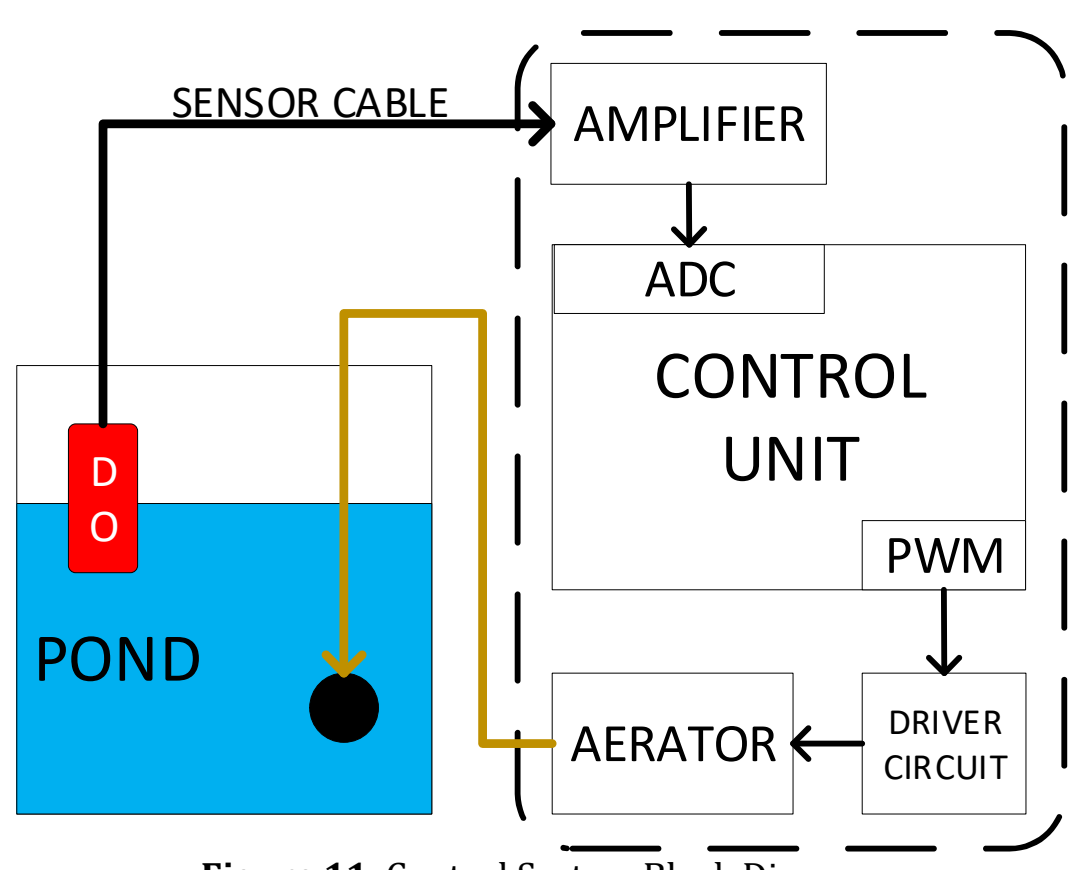

Figure 11. Control System Block Diagram

To maintain the DO in the water, a control method called fuzzy logic controller is used [1]. Fuzzy logic works by calculating the error of measured DO against setting the value of DO and $\Delta$-error that describe the difference between current error and previous error. The block diagram of the fuzzy logic-based controller is shown in Fig. 12.

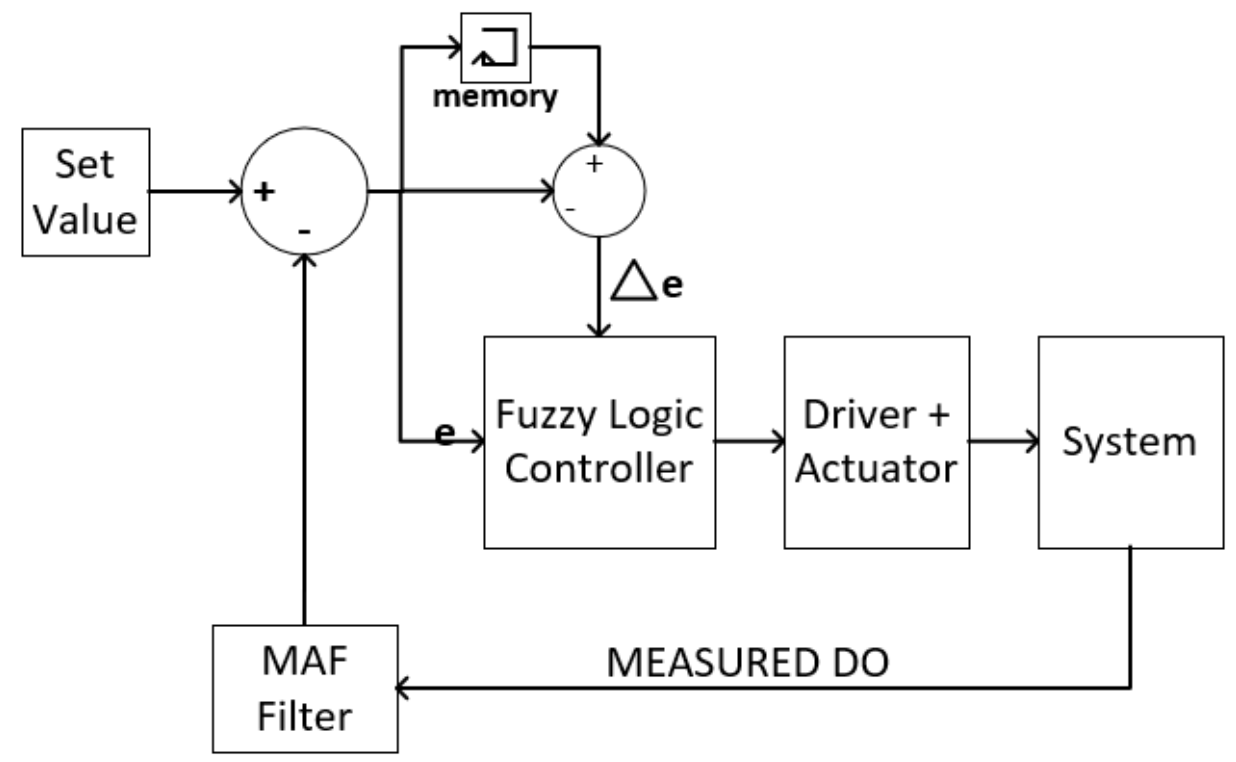

Figure 12. Block Diagram of Fuzzy Logic Controller 
As shown in Fig. 12, measured DO is send back to the system as feedback for calculation. A moving average filter (MAF) with 30 order filter is used to remove the noise which comes with the signal data. Then, error and $\Delta$-error is obtained by calculating the difference between measured DO and DO set point. Fuzzy logic has been used in [25][26] to compute multiple input parameters to estimate a designated output. In this research, a fuzzy logic controller (FLC) computes 2 input parameters which are error and $\Delta$-error of DO to estimate the proper input voltage for aerator in producing air bubbles. To perform this process, FLC follows the membership function of error and $\Delta$-error which are shown in Fig. 13 and Fig. 14 respectively [1].

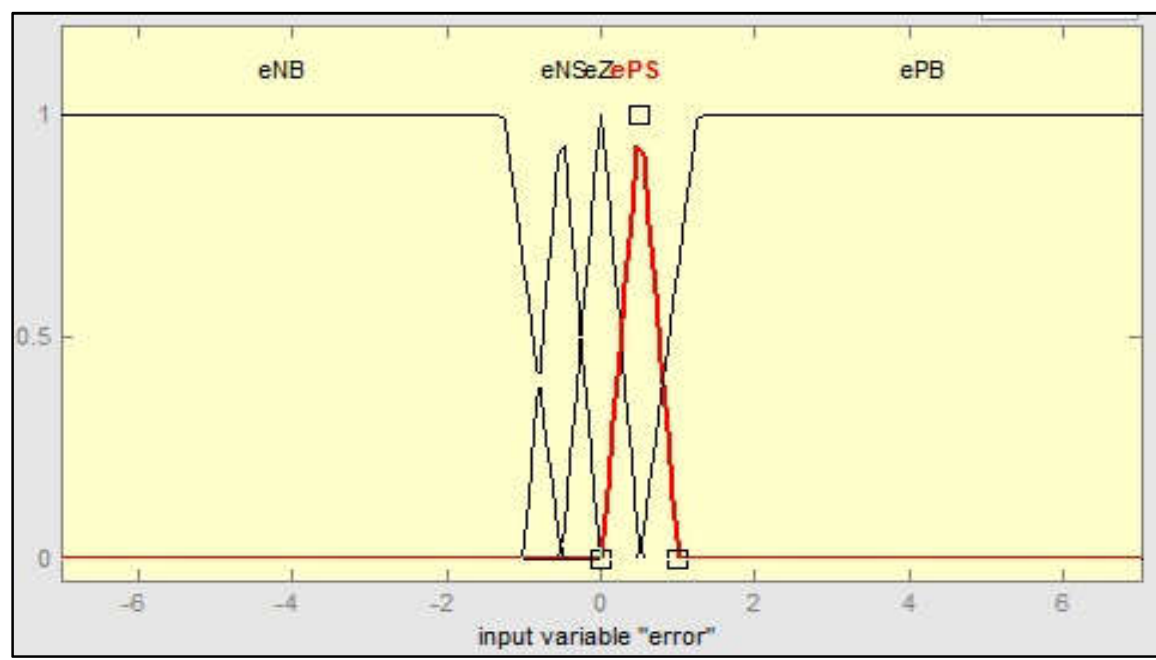

Figure 13. Membership Function Error

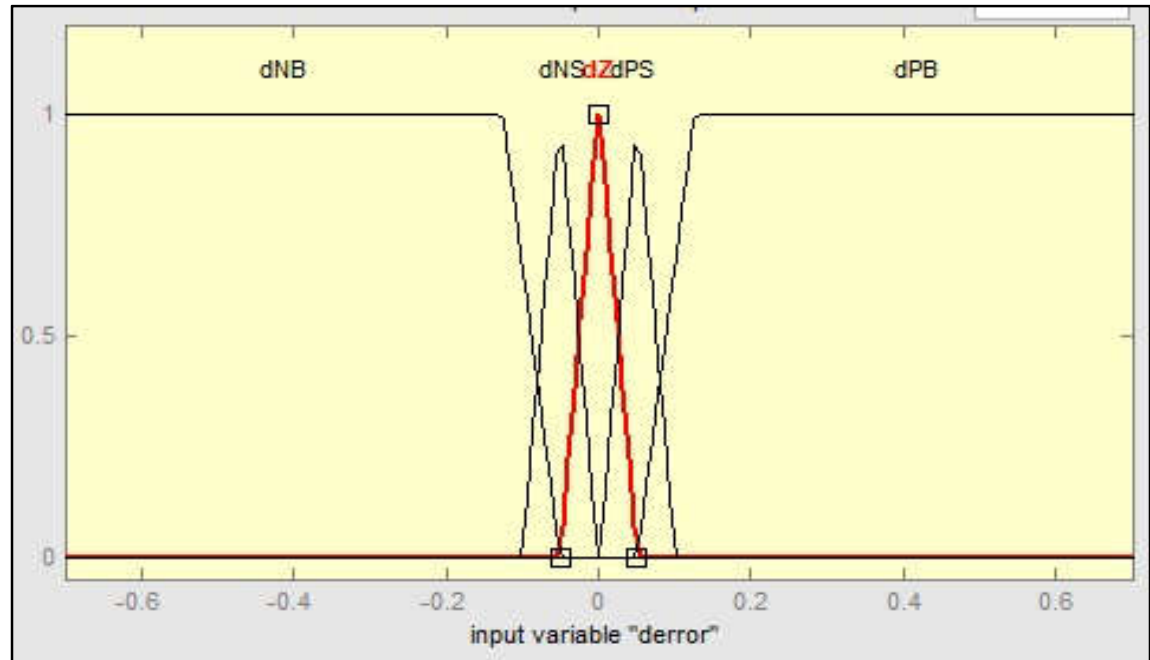

Figure 14. Membership Function $\Delta$-Error

After computing the error and getting the membership for each input value, then a decision for actuating the aerator can be processed based on the rules which are shown in Table 6. Finally, a single tone defuzzification mechanism like shown in Fig. 15 is applied to compute the output value. 
Table 6. Rule Base for Fuzzy Logic Controller

\begin{tabular}{|c|l|l|l|l|l|l|}
\hline \multirow{2}{*}{ Rule } & \multicolumn{5}{c|}{ Error } \\
\cline { 3 - 7 } & eNB & eNS & eZ & ePS & ePB \\
\hline \multirow{2}{*}{} & dNB & poNB & poNB & poNB & poNS & poZ \\
\cline { 2 - 7 } & dNS & poNB & poNB & poNS & poZ & poPS \\
\cline { 2 - 7 } & dZ & poNB & poNB & poZ & poPS & poPS \\
\cline { 2 - 7 } & dPS & poNB & poZ & poPS & poPB & poPB \\
\cline { 2 - 7 } & dPB & poNB & poPS & poPB & poPB & poPB \\
\hline
\end{tabular}

Nomenclature for Table 6.

$\begin{array}{ll}\text { eNB } & \text { : error Negative Big } \\ \text { eNS } & \text { : error Negative Small } \\ \text { eZ } & \text { : error Zero } \\ \text { ePS } & \text { : error Positive Small } \\ \text { ePB } & \text { : error Positive Big } \\ \text { dNB } & \text { : delta error Negative Big } \\ \text { dNS } & \text { : delta error Negative Small } \\ \text { dZ } & \text { : delta error Zero } \\ \text { dPS } & \text { : delta error Positive Small } \\ \text { dPB } & \text { : delta error Positive Big } \\ \text { poNB } & \text { : point of output Negative Big } \\ \text { poNS } & \text { : point of output Negative Small } \\ \text { poZ } & \text { : point of output Zero } \\ \text { poPS } & \text { : point of output Positive Small } \\ \text { poPB } & \text { : point of output Positive Big }\end{array}$

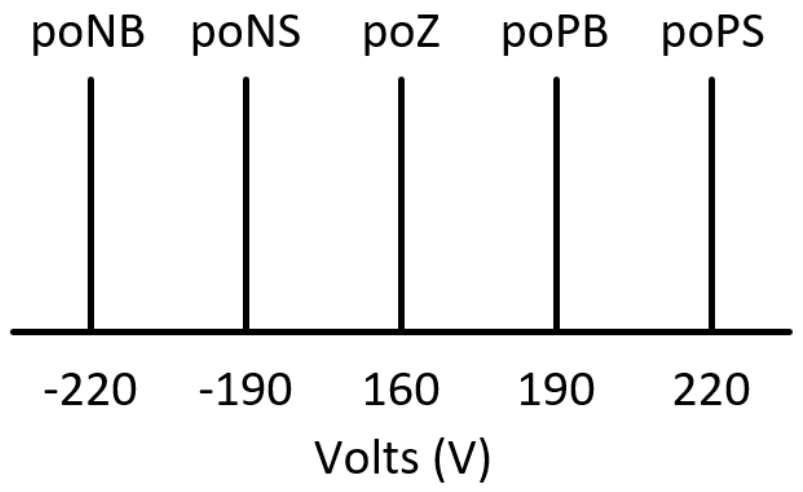

Figure 15. Single Tone Defuzzification

\section{EXPERIMENT AND ANALYSIS}

In this chapter, the test result for each subsystem in WQCM system is described. The test results data is obtained based on the real implementation of the system on indoor shrimp pond. Especially for controller test, several cases are given to the fuzzy controller and its response is observed [1]. 


\subsection{Early Warning Test}

In order to ensure that early warning system works properly, we test it by moving the $\mathrm{pH}$ sensor probe to water tub which contains acidic liquid with a $\mathrm{pH}$ value of 4 and bases liquid with a $\mathrm{pH}$ value of 8.1. Thus, the system detects bad condition for cultivation process and send an early warning SMS to the farmer. Received message of early warning SMS due to water that is too acidic and to bases is shown in Fig. 16.

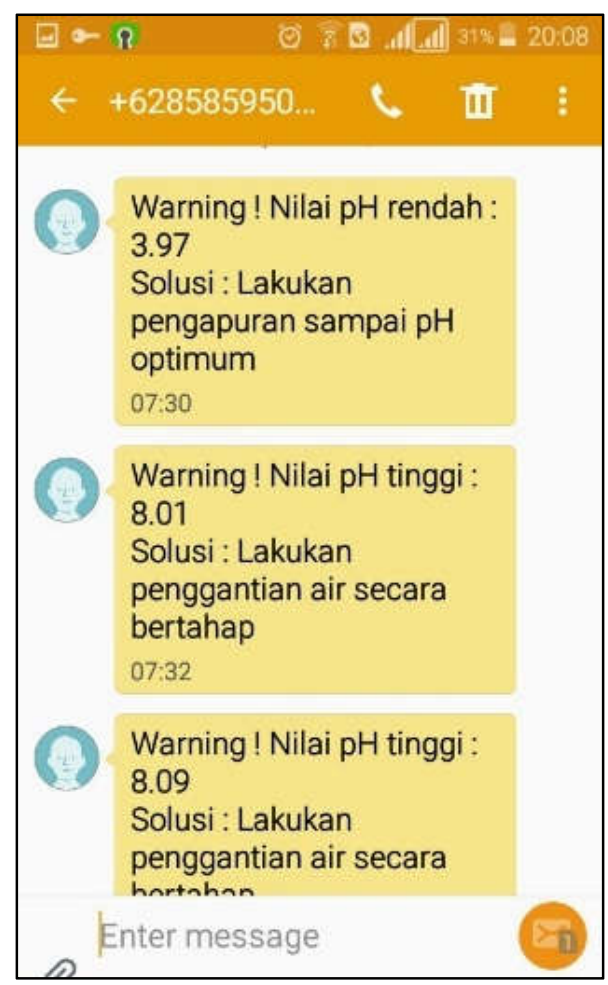

Figure 16. Early Warning SMS due to Acidic Water

*in English: Warning! pH value is low: 3.97. Solution: Perform liming until optimum pH.

*in English: Warning! pH value is high: 8.01. Solution: Perform water circulation gradually.

\subsection{Control System Test}

As in [1], the DO set the set point value is set to $6 \mathrm{ppm}$ and the system is expected to control the air flushing and maintain the stability of DO around the setpoint value. DO response from the lowest state to 6 ppm is shown in Fig. 17 and the response characteristic can be seen in Table 7.

Table 7. DO Response During Control Test

\begin{tabular}{|c|c|c|}
\hline No. & Parameter & Value \\
\hline 1 & Rise Time & 39 seconds \\
\hline 2 & Peak Time & 66 seconds \\
\hline 3 & Settling Time & 178 seconds \\
\hline 4 & Maximum Overshoot & $0.290 \mathrm{ppm}(4.83 \%)$ \\
\hline 5 & Average DO on Steady State & $5.981 \mathrm{ppm}$ \\
\hline 6 & Steady State Error & $0.019 \mathrm{ppm}(0.32 \%)$ \\
\hline
\end{tabular}




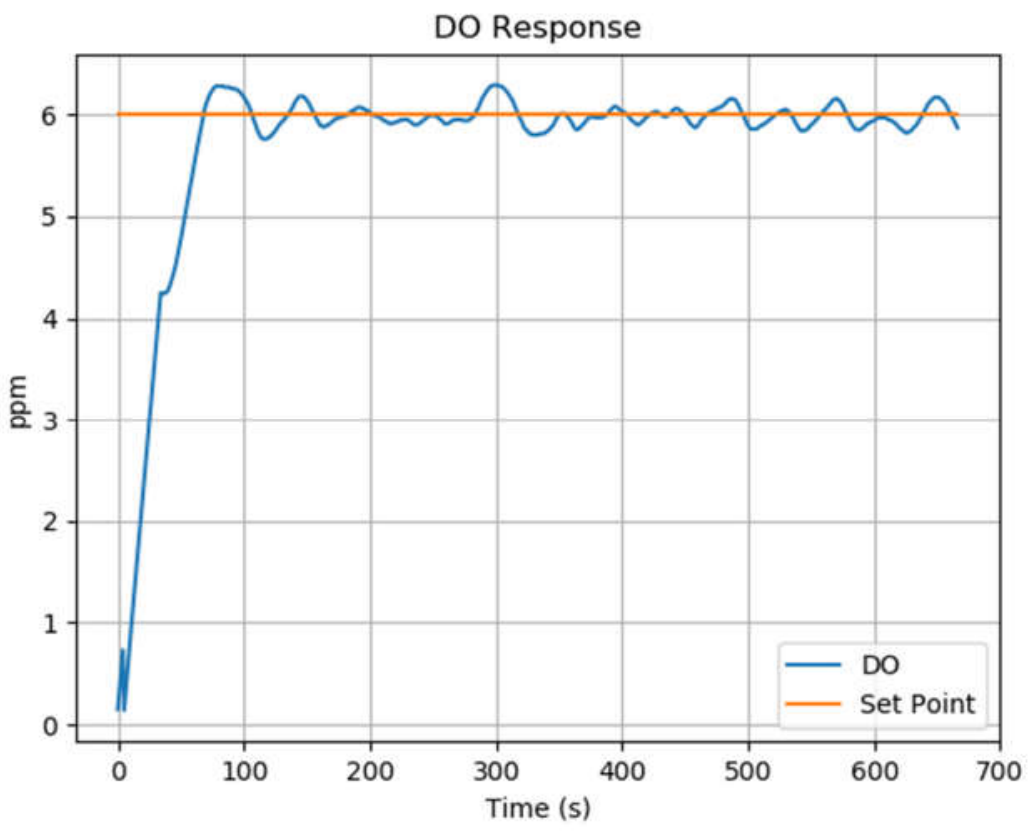

Figure 17. DO Response and Stability

\subsection{Changing-Set Point Test}

In this test, the setpoint value is changed from $6.5 \mathrm{ppm}$ to $6 \mathrm{ppm}$. The goal of this test is to ensure that the system can adapt to changing set point. The DO response from $6.5 \mathrm{ppm}$ to $6 \mathrm{ppm}$ is shown in Fig. 18.

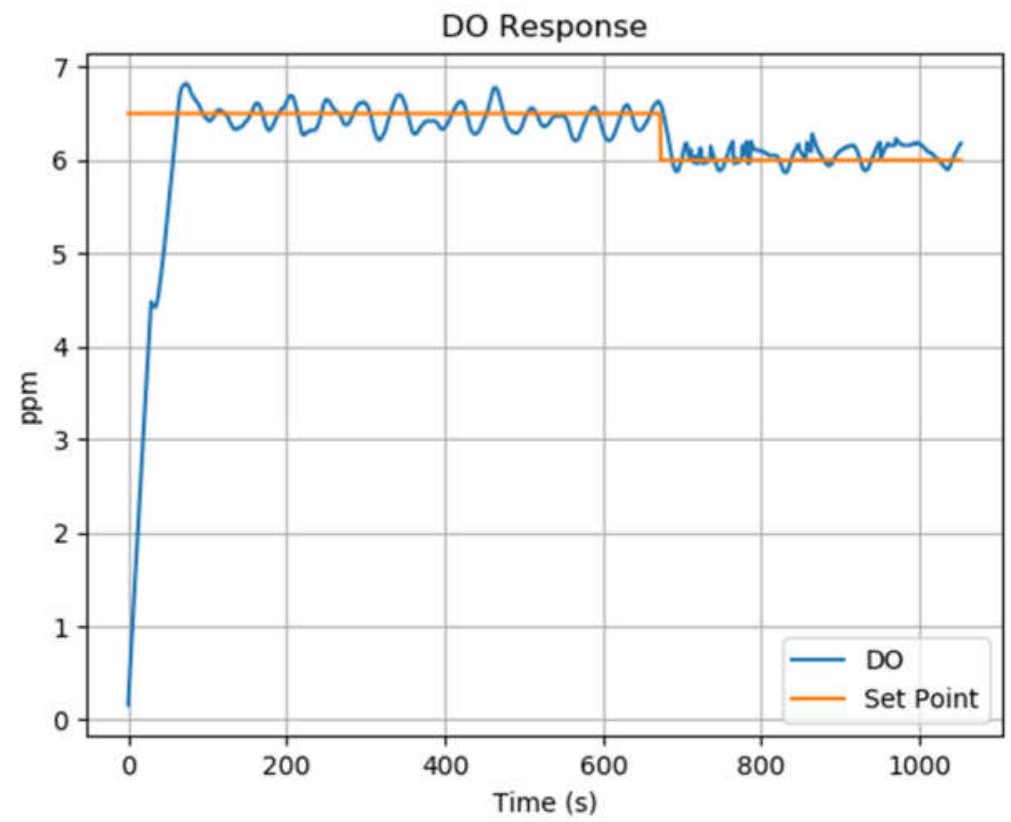

Figure 18. DO Response on Changing-Set Point

As shown in Fig. 18, the average D0 rate when the set point is $6.5 \mathrm{ppm}$ is $6.46 \mathrm{ppm}$ with a maximum overshoot of $0.31 \mathrm{ppm}$. Then the average D0 rate on the setpoint of $6 \mathrm{ppm}$ is $6.13 \mathrm{ppm}$ with a maximum overshoot of $0.28 \mathrm{ppm}$. 


\subsection{Disturbance Test}

This test is used to observe the system response when any disturbance occurred. The disturbance is given by switch the power line off so that the DO rate will decrease due to no aeration process [1]. Then, the power line is switched on again and the system is expected to control the DO automatically. As shown in Fig. 19, the fuzzy logic controller is able to manage the D0 rate back to the setpoint value around $6 \mathrm{ppm}$ after the disturbance is given.

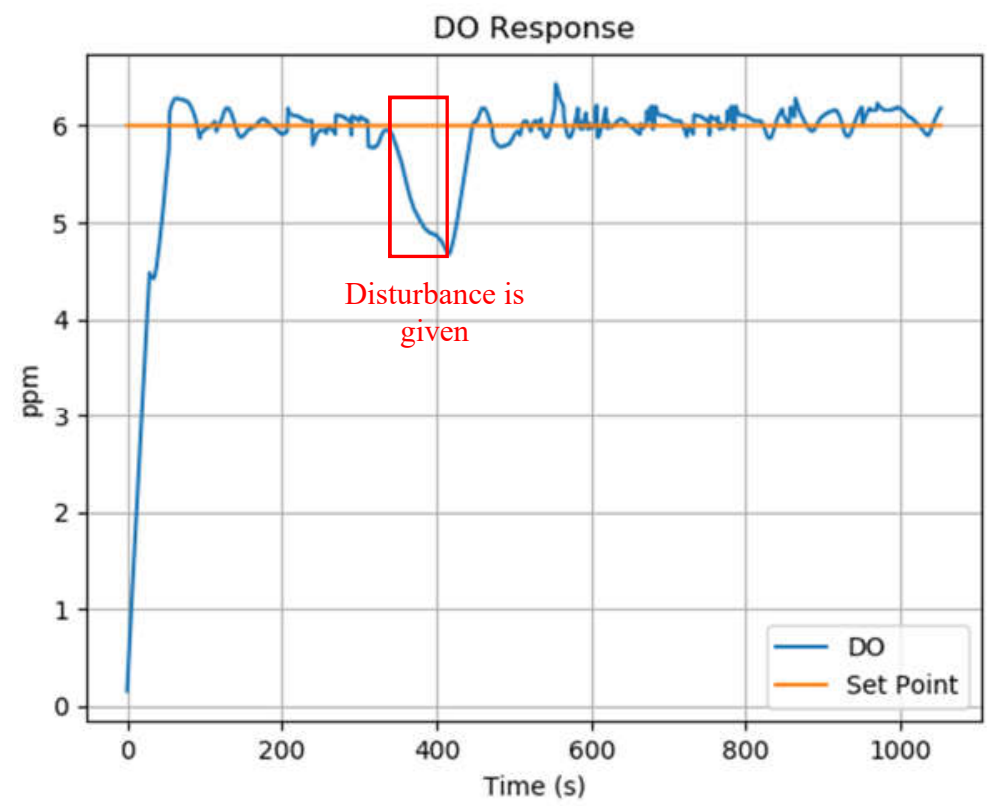

Figure 19. DO Response during Disturbance Test

\subsection{Long-Time Control Test (Robustness Test)}

To test its robustness, the controller is applied for long-time use and expected to manage the DO with stability. To ensure its capability, the DO data is gathered periodically like shown in Table 8. As a result for 2 days control, the average DO value is $6.05 \mathrm{ppm}$ with the standard deviation of $0.12 \mathrm{ppm}$.

Table 8. Long-Term DO Response

\begin{tabular}{|c|c|c|}
\hline No. & Date and Time & Value (ppm) \\
\hline 1 & $07 / 06 / 2018-00: 11$ & 6.14 \\
\hline 2 & $07 / 06 / 2018-04: 11$ & 5.94 \\
\hline 3 & $07 / 06 / 2018-08: 11$ & 6.17 \\
\hline 4 & $07 / 06 / 2018-12: 33$ & 6.08 \\
\hline 5 & $07 / 06 / 2018-16: 33$ & 5.91 \\
\hline 6 & $07 / 06 / 2018-20: 32$ & 6.25 \\
\hline 7 & $08 / 06 / 2018-00: 31$ & 6.01 \\
\hline 8 & $08 / 06 / 2018-04: 31$ & 5.98 \\
\hline 9 & $08 / 06 / 2018-08: 32$ & 5.85 \\
\hline 10 & $08 / 06 / 2018-12: 32$ & 6.01 \\
\hline 11 & $08 / 06 / 2018-16: 32$ & 6.16 \\
\hline 12 & $08 / 06 / 2018-20: 32$ & 6.10 \\
\hline
\end{tabular}




\subsection{Monitoring System and Data Record}

The system is implemented on a shrimp pond to measure water parameters and upload them to cloud storage. The system is tested for 31 days of cultivation to gather the data twice a day. The recorded data of $\mathrm{DO}, \mathrm{pH}$, salinity, and temperature are shown in Fig. $20-23$ respectively.

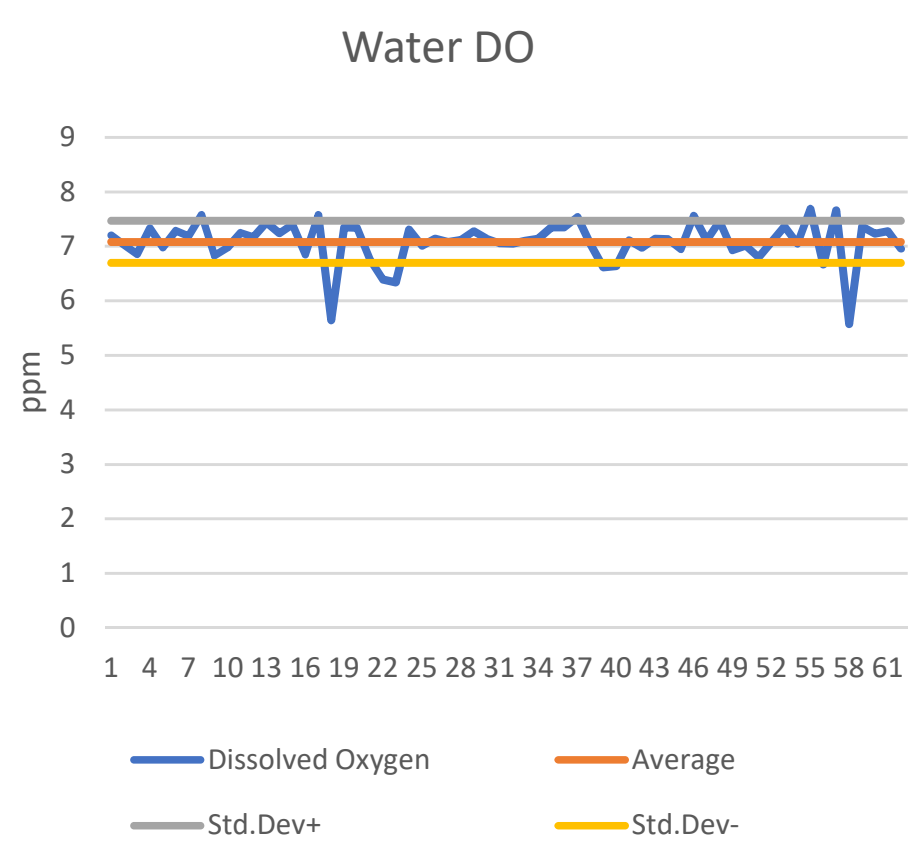

Figure 20. Water DO

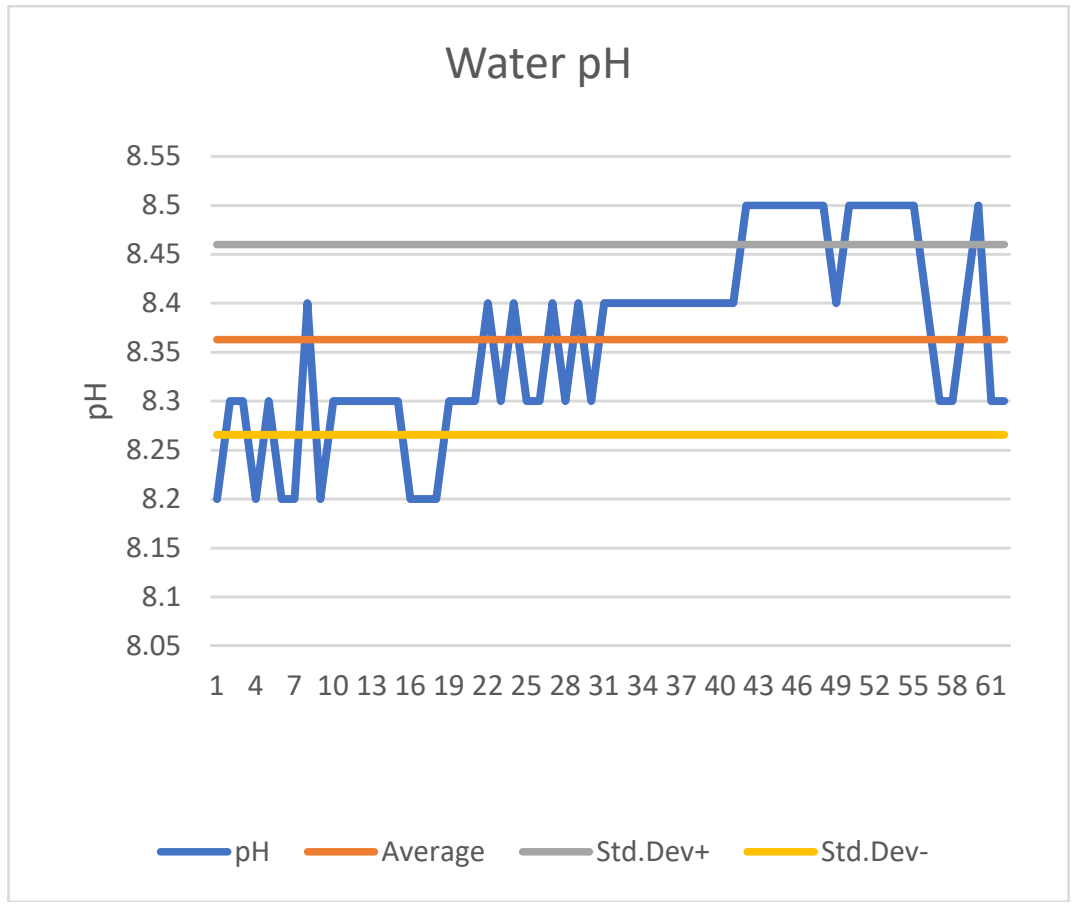

Figure 21. Water $\mathrm{pH}$ 


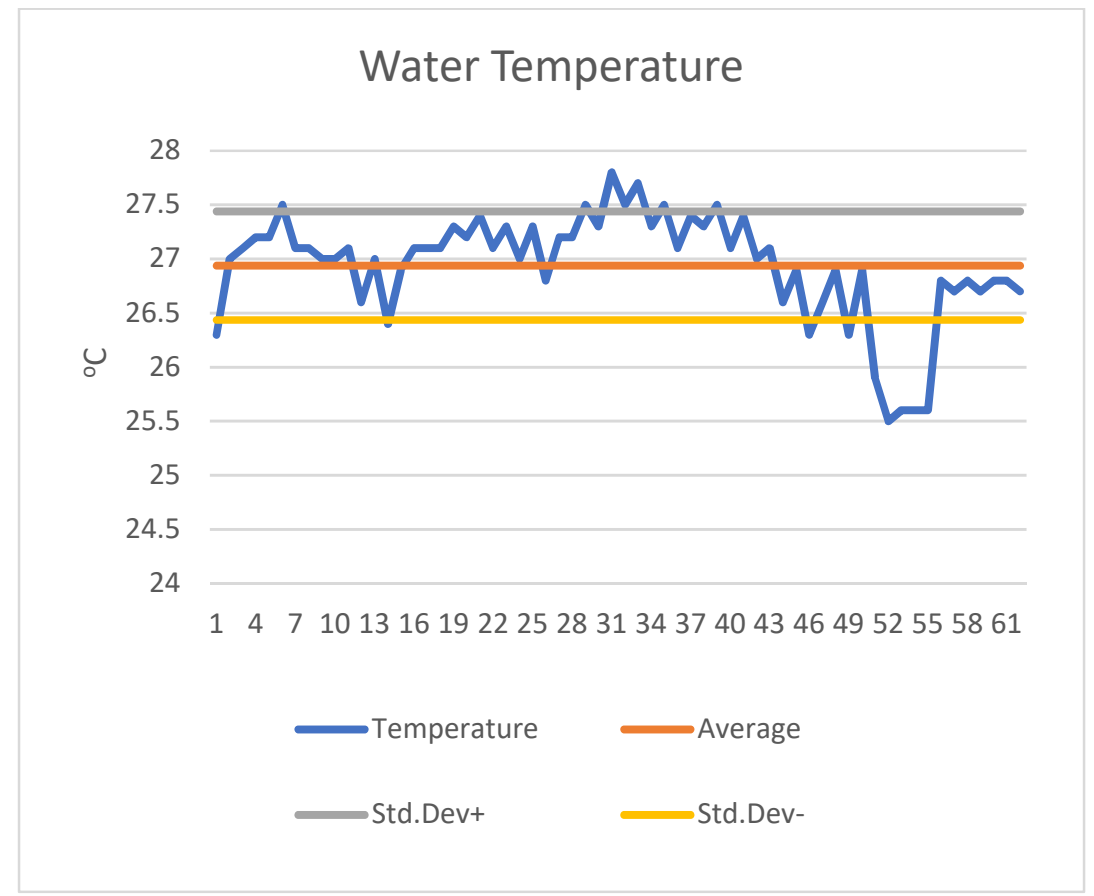

Figure 22. Water Temperature

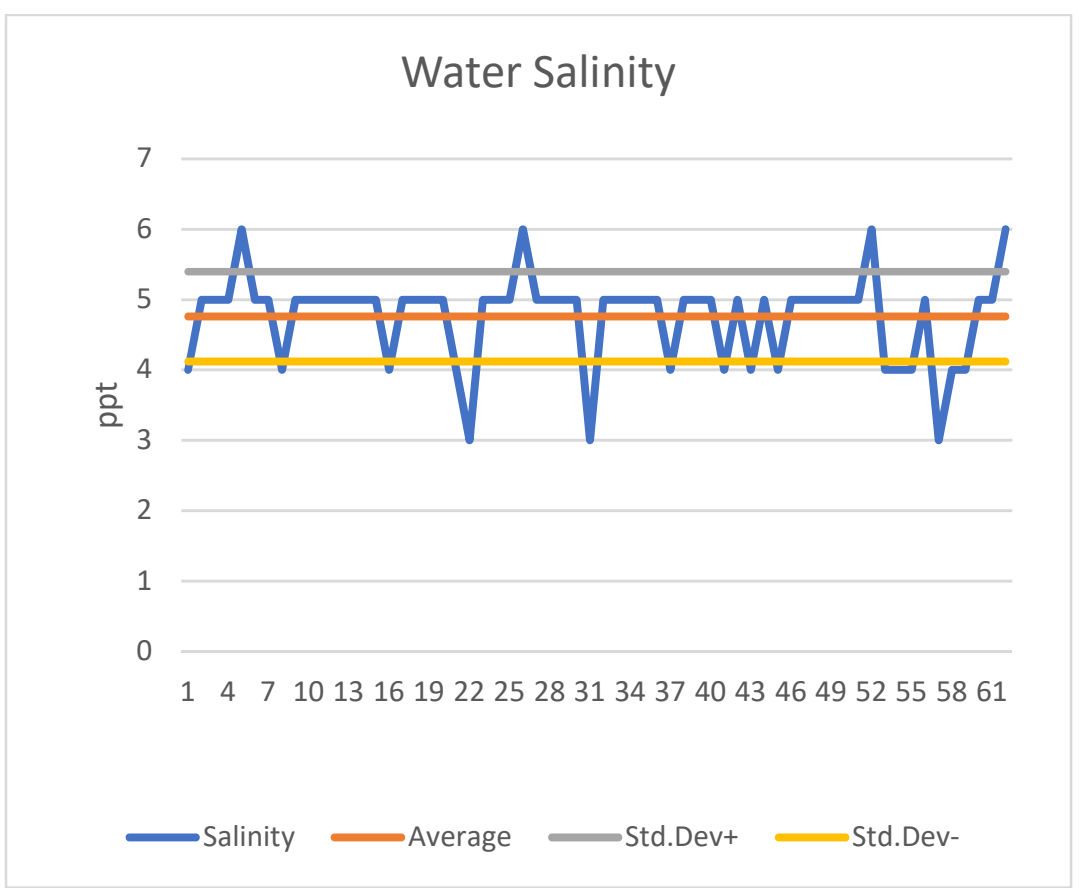

Figure 23. Water Salinity

As shown in Fig. 23, the water salinity is about 5 ppt which is far from the standard in [2]. This condition can be accepted since the type of shrimp seeds is S0-vannamei seeds which can be cultivated in an indoor pond with water salinity below $10 \mathrm{ppt}$. Finally, the summary of statistical data on several water parameters in one month is shown in Table 9. 
Table 9. Summary of Statistical Data

\begin{tabular}{|c|c|c|c|c|}
\hline Parameter & Average & $\begin{array}{c}\text { Standard } \\
\text { Deviation }\end{array}$ & $\begin{array}{c}\text { Max } \\
\text { Value }\end{array}$ & $\begin{array}{c}\text { Min } \\
\text { Value }\end{array}$ \\
\hline $\mathrm{DO}(\mathrm{ppm})$ & 7.08 & 0.38 & 7.69 & 5.57 \\
\hline $\mathrm{pH}$ & 8.36 & 0.10 & 8.50 & 8.20 \\
\hline Temperature $\left({ }^{\circ} \mathrm{C}\right)$ & 26.94 & 0.50 & 27.80 & 25.50 \\
\hline Salinity $(\mathrm{ppt})$ & 4.76 & 0.64 & 6.00 & 3.00 \\
\hline
\end{tabular}

\section{CONCLUSION}

WQCM system is implemented in an indoor shrimp pond and proved to be able to supervise the water quality and maintaining the DO rate base on several experiment results. The DO can be managed around the setpoint value of $6 \mathrm{ppm}$ in 78 seconds. The system is able to adapt when disturbance and setpoint changes are given. The system is also able to be used for a long-time use with the average DO value of $6.05 \mathrm{ppm}$ and small deviation value of 0.12 ppm. Another sub-system such as early warning and monitoring system for a shrimp pond has been introduced. This system can measure water parameters such as DO, pH, salinity, and temperature continuously and upload the data to cloud storage periodically. By using this feature, the farmer doesn't need to keep-an-eye to the pond and record the data manually. Early warning system also worked by sending an SMS to remind the farmer when a bad condition occurred. Last, the Android-based GUI has been proven to support the farmer in understanding the water quality data.

Several problems in the environmental factor and its management have been solved in this research but not for the other factors like feeding treatment and biological factor. Therefore, a further study about feeding and biological treatment is needed to overcome another problem in aquaculture area.

\section{REFERENCES}

[1] D. Yuswantoro, O. Natan, A. N. Angga, A. I. Gunawan, Taufiqurrahman, B. S. B. Dewantara, A. Kurniawan, Fuzzy logic-based control system for dissolved oxygen control on indoor shrimp cultivation, International Electronics Symposium on Engineering Technology and Applications (IES-ETA), pp. 37-42, 2018.

[2] H. Muharijadi Atmomarsono, Supito, Markus Mangampa, and H. W. Pitoyo, Better Management Practice Budidaya Udang Vanamei, 1st ed. Jakarta: WWF Indonesia, 2014.

[3] J. Kaur, G. Jaligama, J. F. Atkinson, J. V Depinto, A. D. Nemura, and A. Drive, Modeling Dissolved Oxygen in a Dredged Lake Erie Tributary, in International Association Great Lakes Res., vol. 33, no. 1, pp. 62-82, 2007.

[4] V. Hull, L. Parrella, and M. Falcucci, Modelling dissolved oxygen dynamics in coastal lagoons, in Ecological Modelling vol. 1, pp. 468480, 2007.

[5] N. Martin, P. Mceachern, T. Yu, and D. Z. Zhu, Model development for prediction and mitigation of dissolved oxygen sags in the Athabasca 
River, Canada, in Science of the Total Environment, vol. 443, pp. 403412, 2013.

[6] P. G. Lee, A Review of Automated Control Systems for Aquaculture and Design Criteria for Their Implementation, in Aquaculture Engineering, Vol. 14, No. 3, pp. 205 - 227, 1995.

[7] Raynitchka Tzoneva, Optimal PID control of the dissolved oxygen concentration in the wastewater treatment plant, AFRICON 2007, Windhoek, 2007, pp. 1-7.

[8] Wei Tang, Qian Feng, Mengxiao Wang, Qian Hou and Leilei Wang, Expert system based dissolved oxygen control in APMP wastewater aerobic treatment process, 2008 IEEE International Conference on Automation and Logistics, Qingdao, 2008, pp. 1308-1313.

[9] A. Zawadzki and R. Piotrowski, Nonlinear fuzzy control of the dissolved oxygen in activated sludge processes, Proceedings of 2012 IEEE 17th International Conference on Emerging Technologies \& Factory Automation (ETFA 2012), Krakow, 2012, pp. 1-7.

[10] L. Fan and K. Boshnakov, Fuzzy logic based dissolved oxygen control for SBR wastewater treatment process, 2010 8th World Congress on Intelligent Control and Automation, Jinan, 2010, pp. 4142-4146.

[11] S. Mirghasemi, C. J. B. Macnab and A. Chu, Dissolved oxygen control of activated sludge biorectors using neural-adaptive control, 2014 IEEE Symposium on Computational Intelligence in Control and Automation (CICA), Orlando, FL, 2014, pp. 1-6.

[12] O. Gehan, E. Pigeon, M. Pouliquen, L. Fall and R. Mosrati, Nonlinear control of dissolved oxygen level for Pseudomonas putida bacterium fermentation, 2016 IEEE Conference on Control Applications (CCA), Buenos Aires, 2016, pp. 1215-1220.

[13] S. Saseendran and V. Nithya, Automated water usage monitoring system, 2016 International Conference on Communication and Signal Processing (ICCSP), Melmaruvathur, 2016, pp. 0099-0103.

[14] X. Fang and K. Zhang, Design and implementation of constant pressure water supply monitoring system based on STM32, 2017 IEEE 17th International Conference on Communication Technology (ICCT), Chengdu, 2017, pp. 1487-1491.

[15] J. Yu, W. Wang, H. Yin, G. Jiao and Z. Lin, Design of Real Time Monitoring System for Rural Drinking Water Based on Wireless Sensor Network, 2017 International Conference on Computer Network, Electronic and Automation (ICCNEA), Xi'an, 2017, pp. 281-284.

[16] A. Anvari, J. Delos Reyes, E. Esmaeilzadeh, A. Jarvandi, N. Langley and K. R. Navia, Designing an automated water quality monitoring system for West and Rhode Rivers, 2009 Systems and Information Engineering Design Symposium, Charlottesville, VA, 2009, pp. 131-136.

[17] Y. K. Taru and A. Karwankar, Water monitoring system using arduino with labview, 2017 International Conference on Computing Methodologies and Communication (ICCMC), Erode, 2017, pp. 416-419. 
[18] K. Gopavanitha and S. Nagaraju, A low cost system for real time water quality monitoring and controlling using IoT, 2017 International Conference on Energy, Communication, Data Analytics and Soft Computing (ICECDS), Chennai, 2017, pp. 3227-3229.

[19] M. Afifi, M. F. Abdelkader and A. Ghoneim, An IoT system for continuous monitoring and burst detection in intermittent water distribution networks, 2018 International Conference on Innovative Trends in Computer Engineering (ITCE), Aswan, 2018, pp. 240-247.

[20] T. Perumal, M. N. Sulaiman and C. Y. Leong, Internet of Things (IoT) enabled water monitoring system, 2015 IEEE 4th Global Conference on Consumer Electronics (GCCE), Osaka, 2015, pp. 86-87.

[21] J. H. Gultom, M. Harsono, T. D. Khameswara and H. Santoso, Smart IoT Water Sprinkle and Monitoring System for chili plant, 2017 International Conference on Electrical Engineering and Computer Science (ICECOS), Palembang, 2017, pp. 212-216.

[22] Y. Eminaga, M. Brischwein, J. Wiest, J. Clauss, S. Becker, and B. Wolf, Sensors and Actuators B : Chemical Self calibration of a planar dissolved oxygen sensor, Sensors and Actuators B: Chemical, vol. 177, pp. 785-791, 2013.

[23] S. Bassini, A. Antonelli, I. Di Piazza, and M. Tarantino, Oxygen sensors for Heavy Liquid Metal coolants : Calibration and assessment of the minimum reading temperature, Journal of Nuclear Material, vol. 486, pp. 197-205, 2017.

[24] B. Sun, P. G. Fitch, I. A. Johns, and G. W. Skyring, Calibration and Field Trial of a Dissolved Oxygen Membrane Electrode: Long-Term Automatic Analyser, Technical Note, vol. 31, no. 2, pp. 362-365, 1997.

[25] B. S. B. Dewantara, J. Miura, Optimizing Fuzzy Rule Base for Illumination Compensation in Face Recognition using Genetic Algorithms, EMITTER International Journal of Engineering Technology, vol. 2, no. 2, pp. 62-79, 2014.

[26] G. Abror, R. T. Widodo, M. U. H A. Rasyid, Dynamic Sleep Scheduling on Air Pollution Levels Monitoring with Wireless Sensor Network, EMITTER International Journal of Engineering Technology, vol. 5, no. 2, pp. 209-233, 2017. 